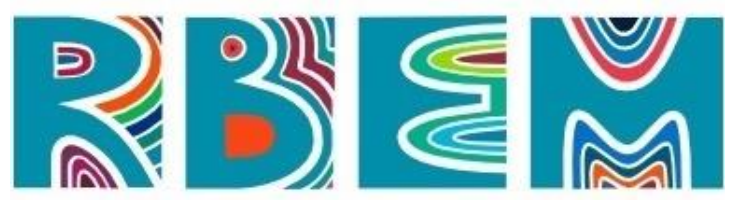

REVISTA BAIANA DE EDUCAÇÃO MATEMÁTICA

ARTIGO

do] https://doi.org/10.47207/rbem.v2i01.10667

\title{
Formação de Professores: $O$ estado do conhecimento no ensino de fração para estudantes surdos
}

\author{
ATAIDE, Clarissa Raimundo de \\ Discente do Curso de Licenciatura Plena em Pedagogia (UNIFESSPA). https://orcid.org/0000-0003-4333-2059. \\ clarissa.ataide2705@gmail.com \\ COSTA, Walber Christiano Lima da \\ Professor da Faculdade de Ciências da Educação (FACED/ICH da UNIFESSPA). Doutor em Educação em \\ Ciências e Matemáticas (PPGECM/IEMCI/UFPA). \\ https://orcid.org/0000-0003-2440-8564.walberchristiano@gmail.com
}

\begin{abstract}
Resumo: Este estudo tem como objetivo central conhecer o panorama das pesquisas que trazem a formação de professores para o ensino de Fração com estudantes surdos. Trata-se de um estudo bibliográfico, de abordagem qualitativa, no escopo do estado do conhecimento, cujas produções foram encontradas no repositório do Catálogo de Teses e Dissertações da Capes. A partir da busca de palavras-chave, foram encontradas 623 Teses e 1547 Dissertações, defendidas entre os anos de 2015 a 2019. A partir de um refinamento, encontramos uma Dissertação que aponta uma afinidade teórica sobre nossa discussão, o que evidencia a importância do tema deste artigo. Os resultados revelam a relevância deste estudo, pois o ensino de fração no contexto dos anos iniciais dos estudantes surdos traz uma perspectiva para o uso da Língua Brasileira de Sinais (Libras) como um fator importante visando à inclusão deste Público Alvo da Educação Especial (PAEE).
\end{abstract}

Palavras-chave: Educação. Séries iniciais. Ensino de Fração. Estudantes surdos.

\section{Initial and continuing education of teachers who work on the inclusion of fractional education for deaf students in the initial grades}

\begin{abstract}
This study has as main objective to know the panorama of the researches that bring the education of teachers for the teaching of Fraction to deaf students. This is a bibliographic study, with a qualitative approach, within the scope of the state of knowledge, whose productions were found in the repository of the Capes Thesis and Dissertations Catalog. From the search for keywords, 623 Theses and 1547 Dissertations were found, defended between the years 2015 to 2019. From a refinement, we found a Dissertation that points out a theoretical affinity about our discussion, which highlights the importance of the theme of that article. The results reveal the relevance of this study, because the teaching of fraction in the context of the initial series of deaf students brings a perspective for the use of the Brazilian Sign Language (Libras) as an important factor aiming at the inclusion of this Target Public of Special Education (PAEE ).
\end{abstract}

Keywords: Education. Initial series. Fraction Teaching. Deaf students.

\section{Formación inicial y continua de docentes que trabajan en la inclusión de la educación fraccionada para estudiantes sordos en los grados iniciales}




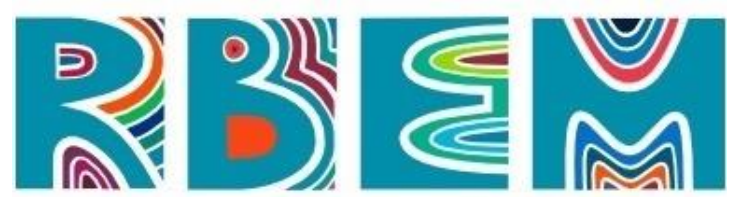

REVISTA BAIANA DE EDUCAÇÃO MATEMÁTICA

Resumen: Este estudio tiene como objetivo central conocer el panorama de las investigaciones que traen la formación de docentes para la enseñanza de la Fracción con estudiantes sordos. Se trata de un estudio bibliográfico, con enfoque cualitativo, en el ámbito del estado de conocimiento, cuyas producciones se encuentran en el repositorio del Catálogo de Tesis y Disertaciones de Capes. De la búsqueda de palabras clave se encontraron 623 Tesis y 1547 Disertaciones, defendidas entre los años 2015 a 2019. A partir de un refinamiento, encontramos una Disertación que apunta una afinidad teórica sobre nuestra discusión, lo que resalta la importancia del tema de este artículo. Los resultados revelan la relevancia de este estudio, ya que la enseñanza de la fracción en el contexto de los años iniciales de los estudiantes sordos brinda una perspectiva para el uso de la Lengua de Signos Brasileña (Libras) como un factor importante para la inclusión de este público meta de la Educación Especial (PAEE).

Palavras-Clave: Educación. Serie inicial. Enseñanza de fracciones. Estudiantes sordos.

\section{Introdução}

O presente estudo busca realizar um levantamento de literaturas, com o intuito de saber quais são os trabalhos científicos que abordam sobre a formação dos professores que ministram a disciplina de matemática, em especial aos profissionais que ministram o conteúdo Fração para estudantes do Público Alvo da Educação Especial (PAEE), com ênfase em estudantes surdos.

Após mencionar o intuito do trabalho, vale ressaltar que ele tem o intuito de buscar trazer conhecimentos e reflexões acerca dos métodos de ensino e aprendizagem de Fração para estudantes surdos que frequentam escolas regulares do município de Marabá-Pará. Paralelamente, este trabalho também cria espaço de inovação em estratégias didáticas de ensino na área da matemática nos anos iniciais.

Documentos oficiais como a Lei de Diretrizes e Bases da Educação Nacional LDBEN 9394/96 (BRASIL, 1996), vem apresentando a formação continuada para professores, como uma forma de aperfeiçoamento contínuo e capacitação para o profissional.

A Política Nacional de Educação Especial dentro do aspecto da Educação inclusiva (BRASIL, 2008), apresenta a justificação do papel do professor como o principal responsável para efetivar uma educação que inclua todos os estudantes, sem acepções, permeando a igualdade entre todos.

É possível encontrar uma rede de literaturas que reforçam uma fundamentação teórica sobre a formação dos professores na perspectiva inclusiva no ensino da matemática, como 


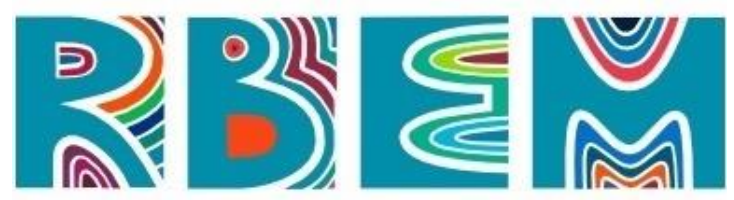

REVISTA BAIANA DE EDUCAÇÃO MATEMÁTICA

D’Ambrosio (1993), Gil (2007), André (2016), Vizolli; Sá (2020), dentre outros grandes autores.

André (2016, p. 32), menciona sua visão a respeito de como o professor precisa agir perante a sua turma em sala de aula, como "[...] aprender a ouvir o outro, a acolher ideias divergentes, a argumentar e a construir projetos comuns, tendo como horizonte o processo educativo dos alunos". Ao considerar a essa proposta da autora, portanto, cabe ao professor saber lidar com essas divergências de ideias que os seus estudantes apresentam dentro da sala de aula.

Nesse sentido, Vigotski (2010) defende a ideia de que o professor deve agir levando em considerando uma organização do seu meio, o que permite compreender a sua maneira de dar aula, ou até mesmo a rotina que costuma seguir, para saber se está fluindo de forma que os estudantes possam se beneficiar. Assim, o professor pode verificar o que precisa ser modificado/organizado, permitindo uma educação com mais qualidade, pois "sobre o professor recai um papel importante. Cabe-lhe tornar o organizador do meio social, que é o único fator educativo" (VIGOTSKI, 2010, p. 448). Em decorrência dessa afirmação, o professor também se destaca como responsável por levar a educação para o seu estudante.

Trazer para esse contexto a importância de debater sobre a formação inicial e continuada dos professores da educação básica com enfoque no ensino do componente curricular matemática, torna-se proeminente, pois esta precisa ser compreendida e ter proveito, como também ser explicada e levada de forma organizada para que todos os estudantes possam entender. D'Ambrosio (1993) apresenta que o professor precisa saber aplicar de forma correta a sua prática dentro da sala de aula, partindo sempre do intuito de incluir todos os estudantes.

Diante disso, o trabalho apresenta o seguinte objetivo central: conhecer o panorama das pesquisas que trazem a formação de professores para o ensino de Fração com estudantes surdos. Para os objetivos específicos, orientou-se: i) verificar enfoques das pesquisas que tematizam a formação de professores que ensinam Fração para estudantes surdos; e ii) identificar os pressupostos teóricos e metodológicos os quais sustentam as pesquisas que tematizam a formação de professores que ensinam Fração para estudantes surdos. 


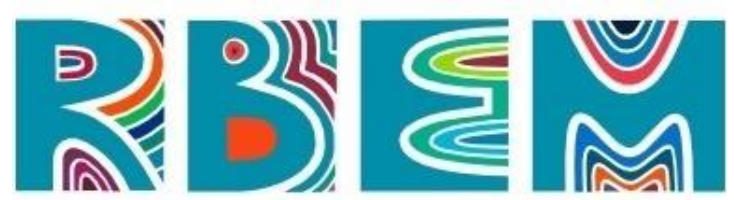

REVISTA BAIANA DE EDUCAÇÃO MATEMÁTICA

\section{Educação matemática para surdos}

Nos últimos anos, o tema educação matemática para surdos tem sido objeto de diversos estudos científicos. Costa (2019) destaca que as duas primeiras Teses de Doutorado sobre esse tema no Brasil (BORGES, 2013; SALES, 2013) marcaram de forma profunda novos pensamentos em educação matemática. Destacamos ainda que Nogueira (1999; 2006), Borges (2006), Healy (2009), Fernandes e Healy (2007; 2016) são outros autores referências na área devido à importância de seus estudos.

Tornar uma aula de matemática significativa para o estudante surdo é permitir a ele oportunidade, voz, interação e vez. Passos, Passos e Arruda (2013, p. 20) relatam sobre tais práticas, pois "pelo que foi encontrado verificou-se que as pesquisas, como já dito anteriormente, focam a aprendizagem dando vez e voz ao aluno com necessidades educacionais especiais", afinal permear ao estudante oportunidades de até mesmo se expressar, já se torna um fator primordial à aprendizagem do estudante do PAEE.

Para Ball, Thames e Phelps (2008), falar do conceito de ensino da matemática não é algo simples como parece ser, pois, para ensinar a disciplina da Matemática, é como se o professor seguisse um processo complexo. Além dos conhecimentos básicos que existe do

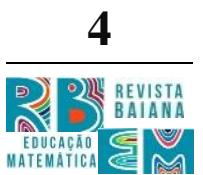
educador, é necessário um conhecimento especializado, pois, assim, o professor conseguirá ampliar o conhecimento pedagógico.

Para o professor fazer das suas aulas mais significativas e compreensivas, ter um curso especializado, conhecer a Língua Brasileira de Sinais (Libras) já é considerável um grande avanço no processo de inclusão, pois vale dizer que, por meio da Libras, existirá a comunicação direta entre o estudante surdo e o professor. Isso contribui para que o surdo se sinta participante ativo em sala de aula, o que fará com que se sinta mais motivado no momento das dúvidas que possam surgir em relação aos conteúdos ministrados durante as aulas.

Em decorrência ao exposto anterior, no que diz respeito aos benefícios de o professor conhecer a Libras, Silva (2014) aponta em suas ideias, o quesito da falta de aperfeiçoamento que ocorre, tornando a situação ainda mais problemática "[...] se a língua não fizer sentido para eles, não conseguiram formular ideias coerentes e, consequentemente, o aprendizado não acontecerá” (SILVA, 2014, p. 30). 


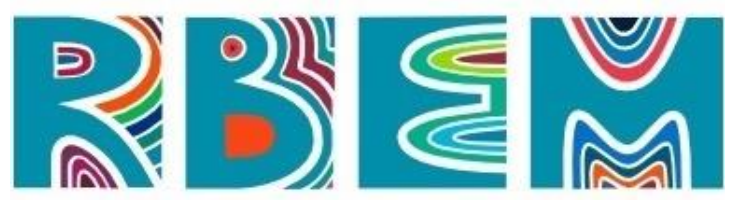

REVISTA BAIANA DE EDUCAÇÃO MATEMÁTICA

É de suma importância ressaltar que a Lei 10.436 (mais conhecida como a Lei de Libras, que entrou em vigor no dia 24 de abril de 2002 e reconhece a Libras como forma de comunicação e expressão das comunidades surdas brasileiras - BRASIL, 2002) aponta no $\operatorname{artigo} 4^{\circ}$

Art. 4o $\mathrm{O}$ sistema educacional federal e os sistemas educacionais estaduais, municipais e do Distrito Federal devem garantir a inclusão nos cursos de formação de Educação Especial, de Fonoaudiologia e de Magistério, em seus níveis médio e superior, do ensino da Língua Brasileira de Sinais - Libras, como parte integrante dos Parâmetros Curriculares Nacionais - PCNs, conforme legislação vigente.

Além da seriedade que a Libras possui, para o desenvolvimento do processo de ensino e aprendizagem, trazer reflexões sobre como as aulas devem ser atrativas para os estudantes surdos (a exemplo de jogos e brincadeiras) são recursos que tendem a tornar o momento de aula mais lúdico, atraente e significativo para o estudante, favorecendo uma aprendizagem mais expressiva. Vale lembrar que, mediante as dificuldades que o próprio conteúdo que a matemática possui, as autoras Teixeira, Moreira e Paiva (2018) defendem a importância e o valor que o jogo possui para a vida do estudante, uma vez que permite uma aprendizagem mais significativa não só para o surdo, como também, aos demais estudantes, pois o aprendizado é promovido por meio de uma atividade prazerosa.

D’ Ambrosio, (1993) também destaca a importância de o professor ter uma aula lúdica, pois assim fará com que as estratégias de ensino possam favorecer não só aos estudantes surdos, mas também permitir que todos os demais tenham um bom rendimento acadêmico nos estudos.

Silva (2014) apresenta em sua Dissertação de Mestrado o conceito de criar alternativas de inclusão. Com isso a autora cria uma espécie de "teleaula de Fração" para que o professor possa ter o contato com o estudante surdo. Nas palavras da autora "[...] buscamos nesta pesquisa criar uma alternativa de teleaula, onde o aluno surdo receberá as informações em sua língua materna" (SILVA, 2014, p.30). Com base nisso, torna-se notório o valor de criarmos alternativas de ensino, que possam viabilizar um ensino adaptado para o estudante surdo, uma vez que a inclusão parte da ação de fazer os conteúdos de ensino acessíveis, para que assim o aluno seja, de fato, incluído. 


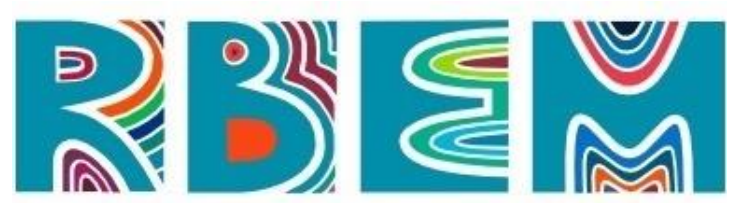

REVISTA BAIANA DE EDUCAÇÃO MATEMÁTICA

O processo de inclusão no ensino de fração e a formação de professores no desenvolvimento de incluir os estudantes surdos

Os métodos pedagógicos de inclusão no processo do ensino de fração

As legislações brasileiras já nos apontam sobre a importância de o professor conhecer o seu estudante e suas condições, pois: “conhecer as condições socioculturais, expectativas e competência cognitiva dos alunos, precisará escolher os problemas que possibilitam a construção de conceitos e procedimentos e alimentar os processos de resolução que surgirem" (BRASIL, 1998, p. 37-38).

Por meio da legislação supracitada, torna-se nítido que ter o conhecimento das diversas condições do estudante gera procedimentos que permitem ao professor poder levar soluções.

Por sua vez, Passos e Nacarato (2018, p. 131) destacam sobre a Base Nacional Comum Curricular (BNCC), publicado em 2017 (BRASIL, 2017) que:

a BNCC avançou ao introduzir novos conteúdos, mas da forma como o fez, não dá subsídios ao professor que não tem uma formação específica para ensinar Matemática e que, o modo como as habilidades foram redigidas dificilmente serão por ele compreendidas. Portanto, muitos são os desafios para a implementação desse documento e são poucas animadoras as ações até aqui apresentadas para garantir o mínimo de conhecimento para o professor trabalhar com segurança (PASSOS; NACARATO, 2018, p. 131).

Embora a BNCC tenha tido alguns avanços, como, por exemplo, a introdução de novos conteúdos de ensino da matemática, é notório perceber no discurso de Passos e Nacarato (2018) o quão ainda tem sido um grande desafio para o professor de Matemática ensinar os conteúdos de tal disciplina. Os autores fazem a alusão a algumas medidas que deveriam ser tomadas, para que haja não somente o avanço dos novos conteúdos, como também uma melhoria no desenvolvimento das habilidades práticas pedagógicas para o professor, até mesmo podendo promover uma capacitação específica para os educadores da Matemática.

É de sumo valor destacar que Vygotsky (1997) trabalhava com pessoas com deficiência, em específico, crianças com cegueira, surdez e com limitações cognitivas. $\mathrm{O}$ autor defendia a teoria do processo de estimulação e a usava com a criança com deficiência, durante o seu processo de ensino Tal teoria era desenvolvida por meio dos estímulos, a partir 


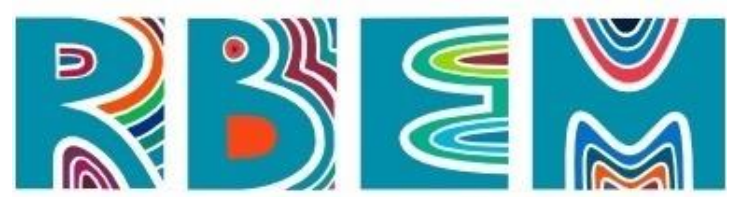

REVISTA BAIANA DE EDUCAÇÃO MATEMÁTICA

do quais a criança teria que procurar os meios e posteriormente superar as barreiras que enfrentava em decorrência das carências que havia dos órgãos sensoriais. Trazendo tal reflexão para os dias de hoje, entendemos que tais estudos têm ajudado os educadores a compreenderem as formas de como trabalhar com o seu estudante com deficiência.

Levando em consideração que os estudantes com deficiência possuem algumas limitações (cognitivas, físicas ou motoras) diante do ensino e aprendizado, torna-se necessário que sejam realizadas algumas adaptações nos processos de ensino e aprendizagem do estudante. Na direção do que apontamos, por exemplo, Neves (2011) defende o valor do trabalho em grupo, atividades lúdicas e atividades que contenham materiais concretos que sejam palpáveis.

Vasconcelos (2010) traz em seu discurso um fator de extrema importância com relação ao valor que as atividades lúdicas possuem. Vejamos a seguir:

[...] Utilizar o recurso aos jogos matemáticos. Os jogos constituem uma forma interessante de propor problemas, pois, permitem que estes sejam apresentados de forma atrativa e favorecem a criatividade na elaboração de estratégias de resolução. Um aspecto relevante nos jogos é o desafio genuíno que eles provocam no aluno, que gera interesse e prazer (VASCONCELOS, 2011, p. 4).

Levando em consideração que o próprio conteúdo da matemática é estimadamente complexo, frisa-se que a proposta de Vasconcelos (2010) mencionada acima permite um aprendizado que envolve o interesse do estudante por meio do método pedagógico dinâmico.

Moreira (2018) discute sobre o ensino de Fração sendo ensinado por meio de brincadeiras, como o jogo da memória e dominó de Fração. A autora também menciona que "Os alunos precisam ser motivados para o início do processo de aprendizagem, [...]" (MOREIRA, 2018, p.53). Em decorrência disso, torna-se evidente o quão é importante a ludicidade para o processo de ensino e aprendizagem do aluno, uma vez que os jogos levam o estudante a uma motivação.

No que se refere ao ensino de Fração, as autoras Silva, Canova e Campos (2016) nos trazem uma breve explicação a respeito do conceito significativo de Fração: "Sabemos que as frações, como os números naturais, são utilizadas para representar quantidades e relações entre quantidades" (SILVA; CANOVA; CAMPOS, 2016, p. 48).

A fim de se tornar um conteúdo dinâmico durante o processo de ensino de Fração para os estudantes surdos, as autoras anteriormente referenciadas, apresentam em seu artigo 


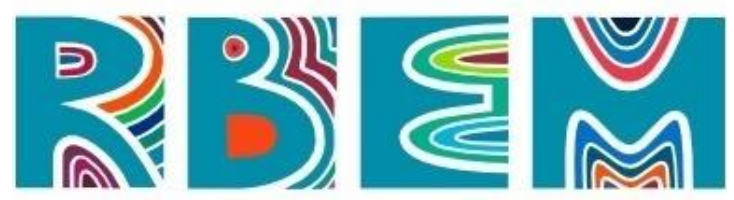

REVISTA BAIANA DE EDUCAÇÃO MATEMÁTICA

um discurso contendo alguns exemplos da utilização de alimentos para poder explicar o ensino de Fração. Como, por exemplo, a pizza, balas, barra de chocolate, copo de água e uma barra de cereal, e, para melhorar o entendimento, abaixo veremos uma representação usando, como exemplo, a barra de chocolate:

Figura 1: exemplo de fração usando a barra de chocolate

Fonte: figura feita pela própria autora, com base na figura do artigo das autoras mencionas no texto.

Mediante ao exemplo exposto anteriormente, os Parâmetros Curriculares Nacionais (PCN), apresentam a importância e o valor que existem ao realizar um ensino trazendo conexões do cotidiano para a disciplina da Matemática, vejamos:

A aprendizagem em Matemática está ligada à compreensão, isto é, à apreensão do significado; apreender o significado de um objeto ou acontecimento pressupõe vê-lo em suas relações com outros objetos e acontecimentos. Assim, o tratamento dos conteúdos em compartimentos estanques e numa rígida sucessão linear deve dar lugar a uma abordagem em que as conexões sejam favorecidas e destacadas. O significado da Matemática para o aluno resulta das conexões que ele estabelece entre ela e as demais disciplinas, entre ela e seu cotidiano e das conexões que ele estabelece entre os diferentes temas matemáticos (BRASIL, 1997, p. 19).

Ainda acerca das formas de como realizar um ensino na matemática, os Parâmetros Curriculares Nacionais também apontam uma vertente a respeito da compreensão do conteúdo que o estudante deve ter nos momentos das aulas ministradas.

Passos e Nacarato (2018, p. 128), em relação à BNCC, explicitam que

No caso de Matemática, na BNCC as competências elencadas aproximam-se das expectativas que defendemos para o ensino; são bastante amplas e contemplam todos os processos matemáticos. Na parte introdutória, o texto sinaliza para a integração das cinco unidades temáticas de Matemática: números, álgebra, geometria, grandezas e medidas e probabilidade e estatística.

Vizolli e Sá (2020, p. 380), ainda em direção ao que discutimos anteriormente, retratam sobre as mesmas questões referentes ao $\mathrm{PCN}$, no que diz respeito ao ensino da matemática (em especial a temática Fração) ser ensinada de forma que possa envolver o cotidiano do estudante: "É importante ensinar o conceito de fração, dedicando mais atenção a 


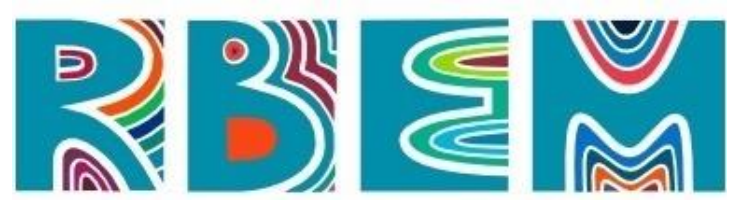

REVISTA BAIANA DE EDUCAÇÃO MATEMÁTICA

atividades de resolução de problemas que envolvem o cotidiano dos estudantes de maneira contextualizada, o que demanda dos professores, estar em constante atualização profissional".

Para Pinheiro (2014, p. 32), “o professor torna-se capaz de refletir criticamente sobre as dificuldades enfrentadas tanto em relação ao ensino quanto à aprendizagem de conteúdos, e no nosso caso específico, do conteúdo frações". No que diz respeito ao posicionamento da autora, vale dizer que essa reflexão é de importância não só para os professores que têm apenas a formação inicial, como também aos que estão em processo da formação a continuada.

\section{A Formação dos professores e as contribuições para o processo de inclusão dos estudantes surdos}

Atualmente, ao tratar sobre educação de surdos dentro da sala de aula, torna-se relevante destacar a eficácia que a Libras tem para promover o processo de inclusão. Sobre o desenvolvimento de educação de surdos e o ensino da matemática, a autora Moreira (2018) destaca a menção do termo educação bilíngue.

Sobre o processo de ensino dentro da matemática, vale dizer que [...] "As pesquisas sobre a ação de professores mostram que em geral o professor ensina da maneira como lhe foi ensinado," (D'AMBROSIO, 1993, p. 38). Com essa afirmação da autora, permite-nos refletir sobre a forma como ocorria a formação dos professores de Matemática na antiguidade, como também nos levam a pensar se de fato o aluno conseguia aprender os conteúdos da matemática.

Borges (2013) traz uma reflexão sobre as dificuldades que os estudantes surdos sentem dentro da sala de aula, e, mediante a tantos enigmas destacados, encontram-se a formação tanto inicial quanto continuada ${ }^{1}$ se fazendo presentes. Borges, (2013, p. 173):

[...] ausência de interação entre surdos e ouvintes no ambiente escolar, falta de definição do papel do tradutor e intérprete de Libras, ausência de atividades que explorassem o aspecto visual no ensino de Matemática e formação inicial e continuada que não contemplavam a inclusão de alunos surdos. Mostraram também

\footnotetext{
${ }^{1}$ Cabe aqui expor o que O Plano Nacional de Educação (PNE) (2001) exibe sobre a formação inicial e continuada para os professores. Para o PNE, aceita-se que o profissional, enquanto educador, faça parte do meio formativo continuado, afinal esse meio de formação permitirá cooperar com o crescimento e conhecimento constante do professor.
} 


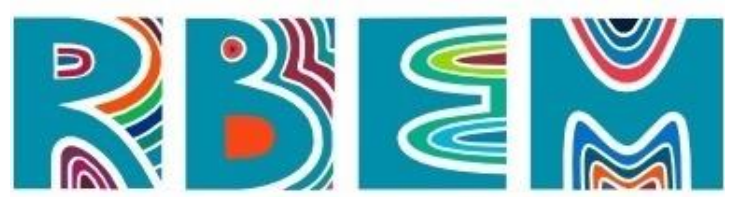

REVISTA BAIANA DE EDUCAÇÃO MATEMÁTICA

dificuldades dos alunos surdos para interpretar enunciados matemáticos devido a desconhecimento dos professores e de outros profissionais.

Ainda com ênfase no contexto anterior, torna-se notório a presença do tema que menciona a formação inicial e continuada na citação acima. Contudo, é de suma relevância que o professor de Matemática se qualifique também em conteúdos de inclusão de estudantes surdos.

Vizolli e Sá (2020) discutem sobre a formação inicial do professor, ressaltando que, quando o profissional é iniciante, recém-formado, a tendência é de o educador focar na prática da matemática, e não na prática do ensinar a matemática. Em decorrência disso, os autores debatem que a tendência nesse período inicial é de o próprio educador propiciar o conteúdo matemático para ele em si receber, em vez de transmitir com eficácia ao estudante.

Em seu artigo sobre a falta de formação especializada que os professores de matemática possuem, Rosa, Rosa, Baraldi (2015, p.186, 187) afirma que "do mesmo modo que o professor de Matemática não foi formado para atender essa nova demanda de alunos, o professor de Educação Especial não tem ou a formação é mínima em relação à Matemática”. Ou seja, de acordo com as autoras, é notório entender que é comum encontrar professores da educação especial que não compreendem sequer o mínimo do componente curricular matemática.

Rosa, Rosa e Beraldi (2015, p.188) mencionam que "O professor é um agente fundamental na educação inclusiva, mas não o único, ele precisa ser incentivado, valorizado e, principalmente, apoiado pela comunidade escolar". Com base nesse discurso das autoras, compreende-se que existe um processo para se chegar na inclusão dos estudantes surdos, levando em conta que o professor, principalmente os considerados antigos na profissão, precisam não somente de um incentivo, mas também de apoio nesse trajeto de qualificação e aperfeiçoamento enquanto educador.

Como sabemos, a formação continuada para professores se faz presente na LDBEN 9.394/96 (BRASIL,1996), oferecendo uma forma de capacitação e aperfeiçoamento contínuo para o profissional da educação brasileira, lembrando que essa mesma lei passa por modificações em 2013 adicionando o termo "treinamento em serviço"2. Com isso, é

\footnotetext{
${ }^{2}$ Refere-se ao documento: Lei $\mathrm{N}^{\circ} 12.796$, de 4 de abril de 2013, a Lei $\mathrm{n}^{\circ} 9.394$ passa por alteração, 20 de dezembro de 1996.
} 


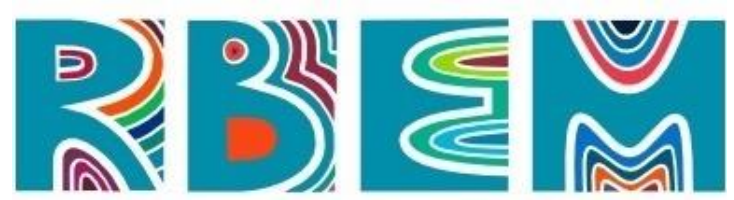

REVISTA BAIANA DE EDUCAÇÃO MATEMÁTICA

necessário que os professores de matemática possam procurar se qualificar ainda mais na área profissional, pois "É necessária uma mudança de postura dos educadores de matemática em relação ao seu ensino" (MOREIRA, 2018, p.39). Assim, entendemos que um professor bem qualificado conseguirá ministrar com eficiência o ensino ao seu alunado.

\section{Metodologia}

Para a produção do artigo, usou-se o método bibliográfico e a abordagem qualitativa, que se baseia em estudos já publicados, como, por exemplo, artigos, Teses, Dissertações, como descrevem Gil (2002), Marconi e Lakatos (2003). Diante disso, pensou-se em realizar um levantamento de trabalhos científicos, para poder usá-los como base de dados e descrever as formas de ensino de Fração que os professores utilizam com estudantes do PAEE, em especial, surdos.

Este estudo vincula-se a um projeto mais amplo desenvolvido por alguns pesquisadores dos Programas de Mestrado e Doutorado em Educação da Universidade Federal do Tocantins (UFT), denominado "Ensino e Aprendizagem de Fração", o qual conta com registro no Comitê de Ética e Pesquisa da UFT, sob o número de protocolo 80769217. 0.

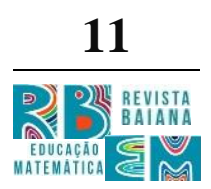
0000. 5519.

Para o desenvolvimento do trabalho, contou-se com um levantamento de estado do conhecimento, fazendo uma busca de Teses e Dissertações já publicadas na plataforma Sucupira $^{3}$. Levando em consideração que a temática do presente trabalho possui as palavraschave: "Formação de professores" + "Fração" + "Surdos", vale dizer que encontraram-se 2170 trabalhos acadêmicos contendo as seguintes divisões: 1547 produções de mestrados e 623 de doutorados, como apresenta o quadro 01 abaixo:

Quadro 01: Quantitativo das produções pesquisadas

\begin{tabular}{|c|c|}
\hline Dissertações: & 1547 \\
\hline Teses: & 623 \\
\hline
\end{tabular}

Fonte: produção de autoria própria - 2021

\footnotetext{
3 A Plataforma Sucupira é uma página na internet de buscar trabalhos científicos. Site Sucupira: https://sucupira.capes.gov.br/sucupira/
} 


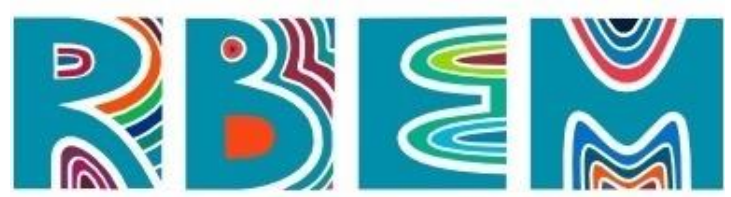

REVISTA BAIANA DE EDUCAÇÃO MATEMÁTICA

Esses trabalhos encontrados estão dispostos nos anos de 2015 a $2019^{4}$, contendo assim três grandes áreas de conhecimentos e quatro áreas de concentração. Vejamos abaixo as descrições detalhadas:

Quadro 02: quantidade de produção em cada ano

\begin{tabular}{|c|c|c|c|c|c|}
\hline Ano & 2015 & 2016 & 2017 & 2018 & 2019 \\
\hline Quantidade & 621 & 653 & 687 & 129 & 80 \\
\hline
\end{tabular}

Fonte: produção de autoria própria - 2021

Quadro 03: área de conhecimento

\begin{tabular}{|c|c|c|c|}
\hline $\begin{array}{c}\text { Área de } \\
\text { conhecimento }\end{array}$ & Educação & $\begin{array}{c}\text { Educação } \\
\text { Especial }\end{array}$ & $\begin{array}{c}\text { Educação de ciências e } \\
\text { matemática }\end{array}$ \\
\hline Quantidade & 1965 & 31 & 174 \\
\hline
\end{tabular}

Fonte: produção de autoria própria - 2021

Quadro 04: área de concentração

\begin{tabular}{|c|c|c|c|c|}
\hline $\begin{array}{c}\text { Área de } \\
\text { concentração }\end{array}$ & Educação & $\begin{array}{c}\text { Educação } \\
\text { matemática }\end{array}$ & $\begin{array}{c}\text { Formação de } \\
\text { professores }\end{array}$ & $\begin{array}{c}\text { Educação do } \\
\text { indivíduo } \\
\text { especial }\end{array}$ \\
\hline Quantidade & 1857 & 174 & 108 & 31 \\
\hline
\end{tabular}

Fonte: produção de autoria própria - 2021

Dentre tais produções descritas e detalhadas acima, dos 2170 trabalhos, apenas 1 apresentou o conjunto dos caracteres mencionados, sendo este: "Formação de professores" + "Fração" + "Surdos". Vale dizer que esse trabalho - intitulado "Intervenções didáticas no ensino de frações e a formação de professores" - é uma Dissertação de mestrado em educação matemática de Francisco José da Silva Junior, disponibilizado no ano de 2015 pela Universidade Anhanguera em São Paulo e foi por nós utilizada para o desenvolvimento desta pesquisa.

A partir dos dados obtidos através da Dissertação de Silva Junior (2015), mostraremos abaixo por meio de um quadro os seguintes pontos: Título da Dissertação; Autor; Ano; Instituto; IES; UF; Linha de pesquisa; Palavras-chaves; Metodologia abordada; Problema investigado e resultados.

\footnotetext{
${ }^{4}$ Utilizou esse recorte temporal a partir da Regra Capes de analisar os trabalhos publicados nos últimos cinco anos. Até a data da produção deste texto, o ano de 2020 ainda não figura nas opções do site, em razão de a coleta Capes ainda estar em andamento.
} 


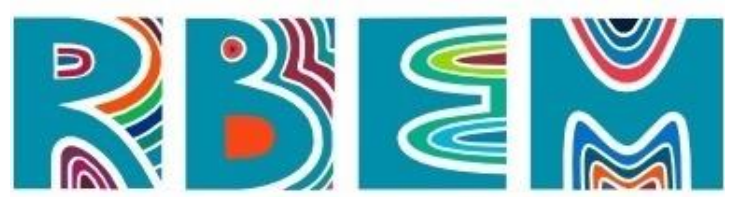

REVISTA BAIANA DE EDUCAÇÃO MATEMÁTICA

Quadro 05: Dissertação de (2015) definida para análise do presente trabalho

\begin{tabular}{|c|c|}
\hline $\begin{array}{l}\text { Título da } \\
\text { Dissertação }\end{array}$ & $\begin{array}{l}\text { Intervenções Didáticas no Ensino de Frações e a Formação De } \\
\text { Professores }\end{array}$ \\
\hline Autor & Francisco José da Silva Junior \\
\hline Ano & 2015 \\
\hline Instituto & Universidade Anhanguera em São Paulo \\
\hline IES & UNIAN \\
\hline UF & São Paulo \\
\hline Linha de pesquisa & Formação de Professores que Ensinam Matemática \\
\hline Palavras-chaves & $\begin{array}{l}\text { Frações. Números racionais. Matemática. Teoria dos Campos } \\
\text { Conceituais. Saberes docentes. Professores reflexivos. }\end{array}$ \\
\hline $\begin{array}{l}\text { Metodologia } \\
\text { abordada }\end{array}$ & Pesquisa de campo - método qualitativo \\
\hline Linha de análise & $\begin{array}{l}\text { Analisar como a formação continuada, desenvolvida na própria escola, } \\
\text { por intermédio da reflexão sobre a prática, pode contribuir para o } \\
\text { desenvolvimento profissional das professoras participantes }\end{array}$ \\
\hline $\begin{array}{l}\text { Problema } \\
\text { investigado }\end{array}$ & $\begin{array}{l}\text { Como a formação continuada, desenvolvida na própria escola, por } \\
\text { intermédio da reflexão sobre a prática, pode contribuir para o } \\
\text { desenvolvimento profissional das professoras participantes. }\end{array}$ \\
\hline Resultados & $\begin{array}{l}\text { Assim, os vídeos foram úteis nesse momento, pois observamos a } \\
\text { necessidade de clarificar para as docentes quais seriam as perspectivas de } \\
\text { trabalho com frações, em discernir o que seria relevante para o início do } \\
\text { trabalho e qual seria a metodologia adequada para fazê-lo. [...] (SILVA } \\
\text { JUNIOR, 2015, p. 67) } \\
\text { [...] Contudo, acreditamos que os vídeos foram mais importantes ainda no } \\
\text { fim da formação, pois, após o desenvolvimento da mesma aula pós- } \\
\text { formação, as professoras tiveram a oportunidade de analisar e comparar a } \\
\text { aula gravada antes da formação com a que haviam ministrado depois. } \\
\text { Funcionou como um espelho de forma a favorecer a observação dos dois } \\
\text { momentos distintos do trabalho docente (SILVA JUNIOR, 2015, p. 67). } \\
\text { [...] iniciamos perguntando às professoras se a formação proposta tinha de } \\
\text { alguma forma ajudado-as a pensarem uma aula diferente. A professora } \\
\text { Fermina foi a primeira a falar dizendo que a resposta era óbvia. Segundo } \\
\text { ela, esses dias em que elas estudaram um ponto específico do programa de } \\
\text { Matemática, no caso de frações, elas haviam se sentido "pessoas } \\
\text { diferentes" [...] (SILVA JUNIOR, 2015, p. 123, 124). } \\
\text { [...]o fato de estarem estudando e ensinando ao mesmo tempo, deu a } \\
\text { impressão de que o conteúdo não era distante da realidade que elas } \\
\text { estavam vivendo[...] (SILVA JUNIOR, 2015, p. 124). } \\
\text { [...] Quando elas chegaram para ensinar fração, segundo ela, o nível de } \\
\text { satisfação e segurança havia chegado ao máximo, porque elas tinham na } \\
\text { cabeça o roteiro de tudo que deveria acontecer, coisa que, } \\
\text { costumeiramente nos anos anteriores, elas não tinham (SILVA JUNIOR, }\end{array}$ \\
\hline
\end{tabular}

Revista Baiana de Educação Matemática, v. 02, n. 01 p. 01-22, e202102, jan./dez., 2021. 
2015, p. 124).

Para as professoras o grande diferencial foi que a formação teve um objetivo claro, determinado dentro do espaço de trabalho delas [...] (SILVA JUNIOR, 2015, p. 126).

[...] No caso dessa formação específica, elas sabiam que em algum momento iriam utilizar o que estava sendo estudado em sala de aula. Segundo elas, esse foi um fator bastante motivador, porque elas puderam estudar durante um período que não foi apressado, que foi construído ao longo de um tempo e aplicaram o aprendido na época certa (SILVA JUNIOR, 2015, p. 126).

Dessa forma, de modo claro observou-se que o estudo sistemático sobre o tema, centrado no trabalho diário de sala de aula, proporcionou reflexões nas professoras que as fizeram modificar a própria prática, fazendo com que elas adquirissem uma intencionalidade que, até então, não possuíam (SILVA JUNIOR, 2015, p. 130).

Destacamos que, durante a formação, nossa intenção foi promover reflexões das participantes sobre os processos de ensino e aprendizagem das frações por meio do contato com resultados de pesquisa, vivência e análise de diferentes situações [...] (SILVA JUNIOR, 2015, p. 130).

A partir da análise dos dados, concluímos que a reflexão sobre a prática é uma grande ferramenta para que o professor aperfeiçoe o seu trabalho docente, pois atende a uma demanda que o professor, por vezes, guarda para si: a necessidade de saber e o receio de demonstrar que não sabe, pelo valor da profissão [...] (SILVA JUNIOR, 2015, p. 130).

Fonte: produção de autoria própria - 2021

A pesquisa de Silva Junior (2015) é um trabalho que foi desenvolvido com duas professoras de matemática e que lecionam em turmas distintas do $4^{\circ}$ ano do ensino fundamental de uma escola particular da cidade de Fortaleza-Ceará. Silva Junior (2015) usa o instrumento de gravação de vídeo para desenvolver os resultados da sua Dissertação. Mediante isso, o autor descreve que esse foi o primeiro passo a ser desenvolvido o seu trabalho. Com as gravações tornou-se possível observar as diferentes formas que as professoras tinham de ministrar aulas sobre o assunto Fração para estudantes surdos.

Na segunda parte da Dissertação, foram realizados 10 encontros de formação com as professoras participantes. O autor deixa claro que o objetivo não era de levar um curso para as professoras de Matemática, mas de permear uma reflexão sobre as práticas de ensino que elas possuem. Como Freire (1996) já dizia “[...] na formação permanente dos professores, o momento fundamental é o da reflexão sobre a prática.” (FREIRE, 1996, p.18).

Para a terceira parte da Dissertação do autor, utilizou-se a técnica da gravação novamente, porém com o intuito distinto do primeiro momento já citado acima. O objetivo 


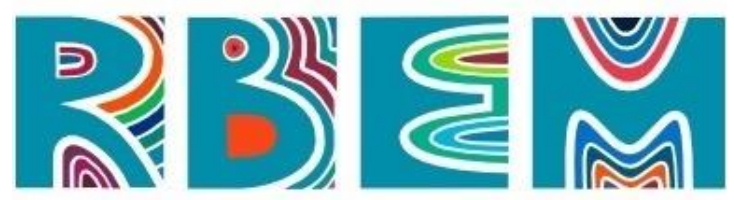

REVISTA BAIANA DE EDUCAÇÃO MATEMÁTICA

nessa terceira parte era de permitir que as professoras voltassem para a sala de aula e ministrarem novamente o assunto Fração, permitindo assim que elas realizassem uma análise após terem tido as reflexões que ocorreram nos encontros de formações de que participaram.

Para análise de dados da dissertação, também contou com narrativas orais e escritas e auxílio de planejamento de aula.

\section{Algumas discussões}

A dissertação de Silva Júnior (2015) conta com a participação de duas professoras de matemática, Fimina e Daza. Como o autor enfatiza mais a participação da primeira, isso nos impele a replicar tal ênfase no desenvolvimento desta pesquisa.

Por meio da professora Firmina ${ }^{5}$, torna-se interessante observar a importância que se tem de realizar um estudo específico sobre o conteúdo que o professor for ensinar em sala de aula. Levando em consideração o documento brasileiro dos Parâmetros Curriculares Nacionais (PCN), este aponta que os problemas de ministrar a disciplina da matemática voltase para os processos de formação ainda no período do magistério, como também, até mesmo, em formação continuada. Vejamos a seguir:

Parte dos problemas referentes ao ensino de Matemática estão relacionados ao processo de formação do magistério, tanto em relação à formação inicial como à formação continuada. Decorrentes dos problemas da formação de professores, as práticas na sala de aula tomam por base os livros didáticos, que, infelizmente, são muitas vezes de qualidade insatisfatória. A implantação de propostas inovadoras, por sua vez, esbarra na falta de uma formação profissional qualificada, na existência de concepções pedagógicas inadequadas e, ainda, nas restrições ligadas às condições de trabalho (BRASIL, 1997, p. 24).

Outros documentos legais, bem como Brasil (2002), apresentam uma percepção específica da forma como se deve ensinar a temática do conceito de Fração.

Deve-se ressaltar que os números fracionários precisam ser mais bem explorados, especialmente em situações práticas, de modo a adquirir significado pelos alunos. É mais importante na 4a série do Ensino Fundamental trabalhar o conceito de fração, explorando suas diferentes possibilidades, inclusive relacionando representações fracionárias e decimais $(=0,5)$ do que lidar com a memorização de procedimentos para realizar operações com frações (BRASIL, 2002, p. 30).

\footnotetext{
${ }^{5}$ Professora Firmina é uma das participantes da pesquisa de dissertação de mestrado de Silva Junior (2015).
} 


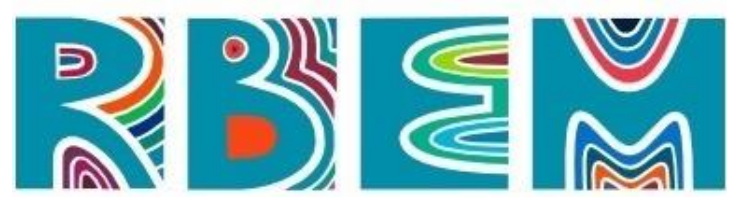

REVISTA BAIANA DE EDUCAÇÃO MATEMÁTICA

É importante salientar que a disciplina Matemática, por si só, apresenta diversos conteúdos complexos. Diante dessa situação, D’Ambrosio (1993) aponta que é de suma importância que o professor passe a promover aulas de acordo com que apresenta Brasil (2002), sendo aulas exploratórias para trabalhar o conceito de frações, assim, os ensinos tornar-se-ão mais significativos para a vida acadêmica do estudante. Silva Junior (2015), discorre que o trabalho exploratório nada mais é do que uma aula que seja significativa para o estudante. $\mathrm{O}$ autor pesquisador também menciona que as professoras participantes da sua dissertação perceberam a necessidade de promover um ensino significativo e, para a promoção dessa aula exploratória e significativa, as educadoras passaram a modificar suas aulas e começaram a abordar assuntos do próprio cotidiano do aluno.

Vale destacar também sobre o benefício que o professor passa a ter quando se estuda e trabalha ao mesmo tempo, uma vez que essa junção facilita a compreensão das formas de como ensinar o estudante e como entender o conteúdo em si. Barros (2018) menciona sobre a seriedade e o valor que se tem quando o professor consegue compreender de forma clara o assunto de fração. Em consonância a isso as professoras participantes da pesquisa de Silva Junior (2015) abordaram sobre a satisfação e a segurança de ensinar fração quando se é estudado e compreendido o conceito de fração antes de ministrar a aula. Com isso, é possível identificarmos uma falta de preparo que os educadores, em especial da matemática, têm tido, até mesmo a falta de entendimento dos próprios assuntos ao qual o profissional escolhe para se profissionalizar.

Cabe aqui ressaltar que a temática formação de professores trouxera para as professoras participantes da dissertação de Silva Junior (2015). Levando em consideração que a formação não tinha como intuito permear um curso, mas sim promover uma reflexão sobre as práticas de ensino do conteúdo Fração, é cabível dizer que os 10 encontros permitiram momentos reflexivos sobre tais práticas, uma vez que as participantes abordaram sobre suas dificuldades e tentaram lidar com elas, gerando assim um aperfeiçoamento no seu processo de ensino de Fração aos estudantes surdos.

$\mathrm{O}$ fato de as aulas serem gravadas também permitiu uma melhoria no processo de ensino, pois ao assistirem às aulas gravadas, foi possível identificar algumas dúvidas no pesquisador, o que possibilitou uma intervenção. Segundo Silva Junior (2015, p.66) “O trabalho de análise dos vídeos deixou-nos dúvidas sobre o planejamento das respectivas aulas. 


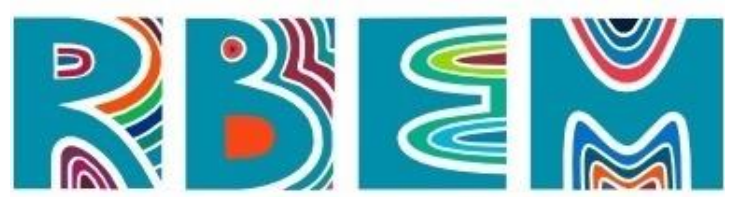

REVISTA BAIANA DE EDUCAÇÃO MATEMÁTICA

Haveria clareza sobre os objetivos de aprendizagem? [...]." Com isso, no nono encontro, o pesquisador convidou as educadoras para que pudessem ver tais práticas e passou as gravações das aulas. Vejamos a seguir a fala das participantes:

A professora Firmina disse que estava ansiosa por esse momento e sabia, segundo ela, que não iria gostar muito de ver a si própria dando essa aula, pois ela tinha mudado muito a opinião sobre o que deveria ter feito. Da mesma forma, a professora Daza disse que estava esperando com ansiedade esse momento, pois sabia, segundo ela, que a aula não tinha sido boa (SILVA JUNIOR, 2015, p. 110).

Após as professoras assistirem às aulas, e por meio de suas falas, tornou-se notório que as educadoras conseguiram identificar a existência de formas inadequadas quando ministraram suas aulas, pois estas não ocorriam de maneira tão satisfatória e/ou acessível para os estudantes. Perceberam que palavras mal usadas por elas podem gerar certa confusão em relação ao entendimento com conteúdo ensinado e à forma de como chega aos estudantes. Com isso, as filmagens despertaram no pesquisador o propósito de realizar um debate acerca das formas de ministração de aulas. Para esse momento, o autor realizou questionamentos, e por meio deles, permeou-se o caminho para reflexões sobre o caso.

Ocorreram também encontros em que foram propostos questionários para que as professoras pudessem responder às perguntas de acordo com as colocações do autor. No entanto, as participantes da pesquisa optaram por que esses momentos fossem de diálogos. Dessa forma, falar sobre tais narrativas orais, durante essa oportunidade, proporcionou o apontamento do tema formação inicial. Em relação a Tal temática, quando abordada, ambas as professoras participantes se mostram insatisfeitas com a forma que eram sujeitas a seguirem a grade curricular no período da graduação. Vejamos:

Passamos então a discutir o aprendizado de matemática na formação inicial, quando as docentes se preparavam na faculdade para assumirem a profissão. Sobre o assunto, elas demonstraram uma ligeira insatisfação com o currículo a que foram submetidas na faculdade (SILVA JUNIOR, 2015, p.71,72).

Um fator importante que as professoras mencionaram consiste na forma como ocorreu o processo de formação inicial para elas, levando em consideração que tal formação teve uma limitação de conteúdo. Em outras palavras, há um limite de conhecimento apenas dentro do espaço do conteúdo da matemática. Já nas demais formações, costumamos presenciar que o objetivo é expor com clareza e detalhes, e não de apenas informar de maneira geral, proposto 


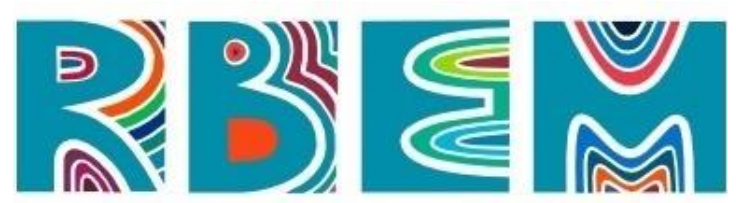

REVISTA BAIANA DE EDUCAÇÃO MATEMÁTICA

por Silva Junior (2015).

O pesquisador apresentou e trabalhou com as professoras o método da reconstrução do plano de aula para executar com os estudantes. Silva Junior (2015, p.32) salientou dizendo: “[...] Nelas, as docentes relataram como se sentiram participando da experiência e como a aula replanejada havida sido afetada pelo percurso da formação e contato com as ideias dos teóricos, até então desconhecidas por elas”. Em decorrência disso, torna-se evidente a importância de reformular um plano de aula quando não aplicado de forma adequada. Para o autor um plano de aula deve ser bem estruturado, para posteriormente ser seguido, já para a professora Firmina, primeiramente era preciso uma mudança interna.

A dissertação apresentou um olhar mais voltado para as práticas das professoras do que para as formas metodológicas de darem aulas, embora os momentos de reflexões e debates que ocorreram durante o processo da formação viessem gerar mudanças de concepções, favorecendo, assim, uma melhoria na carreira enquanto educadora. Como descreve Garcia Silva (2007, p. 9) apud Silva Junior (2015) no que se refere à mudança de concepção “(...) para romper crenças e concepções dos professores sobre ensino e aprendizagem da Matemática e em específico do objeto matemático Fração, é necessária uma constante reflexão sobre a prática, sobretudo em ambientes que propiciem um trabalho colaborativo."

Portanto, torna-se relevante pesquisar temas correlacionados à temática formação de professores e o ensino de Fração para estudantes surdos, pois conhecer e poder apresentar todos os processos que norteiam o desenvolvimento do ensino e aprendizagem do estudante com relação ao conteúdo Fração, converge para uma temática significativa aos profissionais da área da Matemática, uma vez que essa disciplina deve ser explicada de forma lúdica para que o estudante receba de forma expressiva.

\section{Considerações Finais}

Os fatos apresentados e discutidos nesse estudo são análises do percurso de duas professoras de matemática que participaram da pesquisa de Dissertação de mestrado de Francisco José da Silva Junior, a qual foi realizada em uma escola de rede privada do ensino fundamental da cidade de Fortaleza- Ceará. 


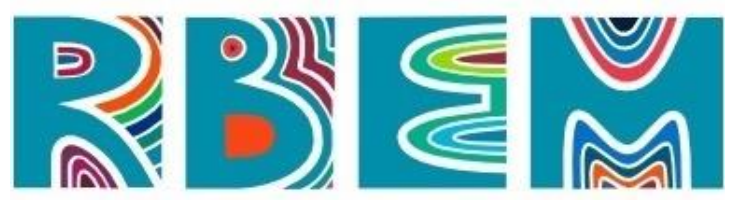

REVISTA BAIANA DE EDUCAÇÃO MATEMÁTICA

Como o objetivo central de nosso trabalho é voltado para conhecer o panorama das pesquisas que trazem a formação de professores para o ensino de fração com estudantes surdos, evidenciou-se que esse percurso de conhecer se fez presente em todas as etapas do processo do nosso estudo.

Por meio das análises que o pesquisador aponta das práticas das professoras, fica evidente que as educadoras ressignificaram as suas práticas no que diz respeito o conteúdo fração. Silva Junior (2015), assim, facilitou às professoras compreenderem uma forma de ensino mais eficaz para o estudante e contribuiu para que o estudante viesse aprender a temática de maneira mais significativa.

Logo, as reflexões de práticas que ocorreram durante os encontros de formação, cooperaram para que as professoras viessem a compreender os diferentes modos de práticas de ensino, como também contribuiu com a abrangência da unificação entre estudo (teoria) e trabalho ao mesmo tempo.

Como relação aos objetivos específicos propostos neste trabalho (I. verificar enfoques das pesquisas que tematizam a formação de professores que ensinam Fração para estudantes surdos; e II. identificar os pressupostos teóricos e metodológicos que sustentam as pesquisas que tematizam a formação de professores que ensinam Fração para estudantes surdos), cabe mencionar que ambos foram discorridos durante todo o processo de desenvolvimento do estudo, desde os primeiros passos que foram os levantamentos de pesquisas bibliográficas, as quais abordam sobre a temática, até a identificação de cada um dos teóricos.

Levando em consideração que este artigo tem a temática que abrange os conceitos: Formação de professores, estudantes surdos e ensino de fração, esperamos contribuir na qualificação de estudos entre professores e até mesmo com estudantes graduandos, como também momentos de debates e que seja um incentivo para mais trabalhos nessa área ao qual percebemos o quanto é pouco abordada. Além disso, esperamos que possamos conseguir incluir todos os estudantes, em especial os surdos, favorecendo o cenário da educação matemática inclusiva. 


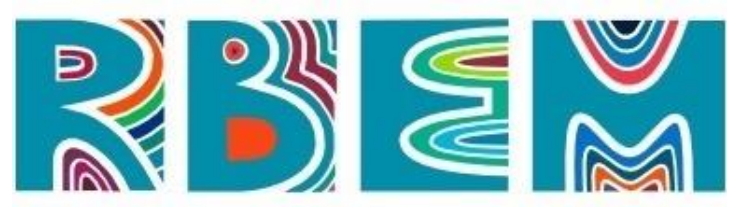

REVISTA BAIANA DE EDUCAÇÃO MATEMÁTICA

\section{Referências}

BALL, D. L.; THAMES, M. H.; PHELPS, G. Content Knowledge for Teaching: what makes it special? Journal of Teacher Education. v.59, n.5, p.389-407, 2008.

BORGES, F. A. A educação inclusiva para surdos: uma análise do saber matemático intermediado pelo Intérprete de Libras. 2013, 260 f. Tese (Doutorado Em Educação para a Ciência e a Matemática) Universidade Estadual de Maringá, 2013.

BORGES, F. A. Institucionalização (sistemática) das representações sociais sobre a "deficiência" e a surdez: relações com o ensino de ciências/ Matemática. Dissertação (Mestrado Em Educação para a Ciência e Ensino de Matemática) Universidade Estadual de Maringá, Maringá/PR, 2006.

BRASIL, Ministério da Educação e do Desporto, Secretaria de Educação Fundamental. Parâmetros Curriculares Nacionais: Matemática (1a a 4a série). Brasília-DF, 1997.

BRASIL. Ministério da Educação. Secretaria de Educação Fundamental. Parâmetros curriculares nacionais: Matemática. Brasília, DF: MEC/SEF, 1998.

BRASIL, Ministério da Educação e do Desporto, Sistema de Avaliação da Educação Básica. SAEB 2001: Relatório SAEB 2001- Matemática. Brasília-DF: MEC/SAEB, 75p, 2002.

BRASIL. Ministério da Educação. Secretaria de Educação Especial. Política nacional de educação especial na perspectiva da educação inclusiva. Brasília, DF, 2008.

COSTA, W. C. L. da. O modelo referencial da linguagem na Tradução-Interpretação da linguagem Matemática pelos surdos usuários da LIBRAS. 2019. Tese (Doutorado) Programa de Pós-Graduação Em Educação em Ciências e Matemáticas. Universidade Federal do Pará, Belém - PA, 2019.

D’AMBROSIO, B. Formação de Professores de Matemática. Pro-Posições. Vol. 4 Nº 1[10]. Março, 1993.

FERNANDES, S. H. A. A.; HEALY, L. Ensaios sobre a inclusão na Educação Matemática. Revista iberoamericana de educação matemática, 2007. n. 10, p.5976.

FERNANDES, S. H. A. A.; HEALY, L. Rumo A Educação Matemática Inclusiva: Reflexões Sobre Nossa Jornada. REnCiMa, Edição Especial: Educação Matemática, v.7 , n.4, p. 28-48, 2016.

FREIRE, P. Pedagogia da Esperança: Um reencontro com a pedagogia do oprimido. Rio de Janeiro: Paz e Terra, 1993.

GARCIA SILVA, A. da F. O desafio do desenvolvimento profissional docente: Análise da formação continuada de um grupo de professores das séries iniciais do Ensino Fundamental, tendo como objeto de discussão o processo do ensino e aprendizagem de frações. Tese 


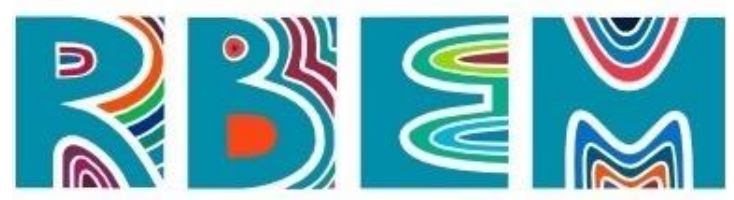

REVISTA BAIANA DE EDUCAÇÃO MATEMÁTICA

(Doutorado em Educação Matemática) - PUC/SP, São Paulo, 2007.

GIL, R. S. A. Educação matemática dos surdos: um estudo das necessidades formativas dos professores que ensinam conceitos matemáticos no contexto de educação de deficientes auditivos em Belém do Pará. 2008.191f. Dissertação de Mestrado em Educação em Ciências e Matemática - Universidade Federal do Pará, Belém, 2007.

HEALY, L. Rumo à Educação Matemática Inclusiva. Projeto de Pesquisa financiado por CAPES (PROESP). São Paulo-SP, 2009.

NOGUEIRA, C. M. I. A Matemática como contribuição educacional ao desenvolvimento cognitivo da criança surda. In: BERGAMASCHI, R.I.; MARTINS, V.R. (Org.). Discursos atuais sobre a surdez: II Encontro a propósito do fazer, do saber e do ser na infância. Canoas: La Salee, 1999, p. 81-113.

NOGUEIRA, C. M. I. As mútuas implicações entre surdez, linguagem e cognição. In: Anais do Encontro Nacional de didática e prática de ensino. Recife, 2006.

ROSA, E. A. C, ROSA, F. M. C, BARALDI, I. M. Professores que ensinam Matemática:

considerações acerca da Inclusão Escolar a partir de duas pesquisas, Revista InFor, n.1, 2015.

PASSOS, C. L. B.; NACARATO, A. M. Trajetória e perspectivas para o ensino de

Matemática nos anos iniciais. Estud. av. , São Paulo, v. 32, n. 94, pág. 119-135, dezembro de 2018. Disponível em <http://www.scielo.br/scielo.php?script=sci_arttext\&pid=S010340142018000300119\&lng=en\&nrm=iso>. acesso em 26 de janeiro de 2021. http://dx.doi.org/10.1590/s0103-40142018.3294.0010.

SALES, E. R. de. A visualização no ensino de matemática: uma experiência com alunos surdos. 2013, 235 f. Tese (Doutorado em Educação Matemática).Rio Claro-SP: Universidade Estadual Paulista., 2013.

SALES, E. R. Refletir no silêncio: um estudo das aprendizagens na resolução de problema aditivos com alunos surdos e pesquisadores ouvintes. 2008. 162 f. Dissertação (Mestrado em Educação em Ciências e Matemáticas) - Programa de Pós-Graduação em Educação em Ciências e Matemáticas, Núcleo Pedagógico de Apoio ao Desenvolvimento Científico, Universidade Federal do Pará, Belém, 2008.

SILVA, E.L. Luz, câmera, ação: adaptando uma teleaula de frações para o público surdo. 2015.107f. Dissertação de Mestrado em Educação Matemática - Universidade Bandeirante Anhanguera, São Paulo, 2014.

SILVA JUNIOR, F. J. da. Intervenções Didáticas no Ensino de Frações e a Formação De Professores' 31/08/2015 147 f. Mestrado em EDUCAÇÃO MATEMÁTICA Instituição de Ensino: Universidade Anhanguera de São Paulo, São Paulo Biblioteca Depositária: UMC

VIGOTSKI, L. S. 1896-1934. Psicologia pedagógica / tradução do russo e introdução de 


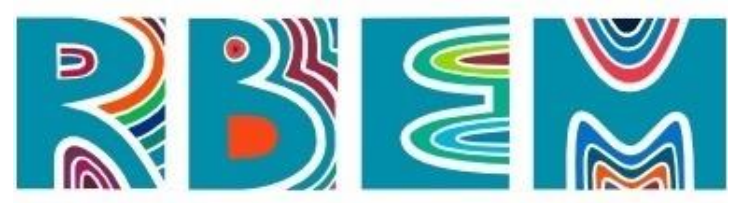

Paulo Bezerra. - $3^{\circ}$ ed. -São Paulo : Editora WMF Martins Fonte, 2010. (Coleção textos da psicologia)

VIZOLLI, I. ; SÁ, P. F. de. Revista REAMEC, Cuiabá (MT), v. 8, n. 3, p. 650- 69, setembrodezembro, 2020. ISSN: 2318-6674. DOI: 10.26571/reamec.v8i3.11022

Artigo submetido em: 03/01/2021

Artigo aceito em: 03/02/2021 